\title{
Urban storage heat flux variability explored using satellite, meteorological and geodata
}

\author{
F. Lindberg ${ }^{1} \cdot$ K. F. G. Olofson ${ }^{1} \cdot$ T. Sun ${ }^{2}$ - C. S. B. Grimmond ${ }^{2}$ - C. Feigenwinter ${ }^{3}$
}

Received: 26 June 2019 / Accepted: 22 March 2020 / Published online: 18 April 2020

(C) The Author(s) 2020

\begin{abstract}
The storage heat flux $\left(\Delta Q_{\mathrm{S}}\right)$ is the net flow of heat stored within a volume that may include the air, trees, buildings and ground. Given the difficulty of measurement of this important and large flux in urban areas, we explore the use of Earth Observation (EO) data. EO surface temperatures are used with ground-based meteorological forcing, urban morphology, land cover and land use information to estimate spatial variations of $\Delta Q_{\mathrm{S}}$ in urban areas using the Element Surface Temperature Method (ESTM). First, we evaluate ESTM for four "simpler" surfaces. These have good agreement with observed values. ESTM coupled to SUEWS (an urban land surface model) is applied to three European cities (Basel, Heraklion, London), allowing EO data to enhance the exploration of the spatial variability in $\Delta Q_{\mathrm{S}}$. The impervious surfaces (paved and buildings) contribute most to $\Delta Q_{\mathrm{S}}$. Building wall area seems to explain variation of $\Delta Q_{\mathrm{S}}$ most consistently. As the paved fraction increases up to 0.4 , there is a clear increase in $\Delta Q_{\mathrm{S}}$. With a larger paved fraction, the fraction of buildings and wall area is lower which reduces the high values of $\Delta Q_{\mathrm{S}}$.
\end{abstract}

\section{Introduction}

The storage heat flux $\left(\Delta Q_{\mathrm{S}}\right)$ is the net flow of heat stored within a volume that includes the air, trees, buildings and ground. The ability to absorb, store and release heat depends on the thermal mass and morphology. In urban areas, the net heat stored in the canopy is a relatively large fraction of the net all-wave radiation $\left(Q^{*}\right)$ compared to other environments (Nunez and Oke 1977; Grimmond and Oke 1999). In highly urbanised areas, it can account for more than half the daytime net all-wave radiation (Oke et al. 1999) and be two to ten times larger than for simple planar surfaces (e.g. soil). The wellknown nocturnal urban heat island (UHI) is caused by the release of stored heat and enhanced by anthropogenic heat $\left(Q_{\mathrm{F}}\right)$. Combined with reduced radiative cooling (or enhanced radiative trapping), the storage heat flux is a major contributor (Oke and Cleugh 1987). Oliphant et al. (2018) demonstrate

F. Lindberg

fredrik1@gvc.gu.se

1 Department of Earth Sciences, University of Gothenburg, Gothenburg, Sweden

2 Department of Meteorology, University of Reading, Reading, UK

3 Institute of Meteorology, Climatology, and Remote Sensing, University of Basel, Basel, Switzerland the importance of building materials such as concrete and asphalt as an essential factor to enhance $\Delta Q_{\mathrm{S}}$, as increased surface roughness using light-weight materials neither affect the storage term nor the UHI. As nocturnal cooling is important for recovering from daytime heat stress (Rocklöv et al. 2011; Thorsson et al. 2014), the expected increases in both urban population (UN 2015) and heat wave frequency (Schär et al. 2004) will likely cause increased heat stress and heatrelated morbidity and mortality.

In simple environments, the storage heat flux can be directly measured using heat flux plates buried a few centimetres below the surface with temperature sensors above to determine the flux divergence. However, in complex urban landscapes, this approach is impractical at the local scale. There are a range of methods to assess the storage heat fluxes in urban areas, including OHM, Objective Hysteresis Model (Grimmond et al. 1991; Grimmond and Oke 1999); AnOHM, Analytical Objective Hysteresis Model (Sun et al. 2017); RES, Residual, determination of the storage heat flux from the residual of the surface energy balance (Offerle et al. 2005b); CAR, Complete Aspect Ratio (Rigo and Parlow 2007); TEB, Town Energy Balance model (Masson 2000) or other urban land surface models; and ESTM, Element Surface Temperature Method (Offerle et al. 2005a). Some methods (e.g. OHM, CAR) use bulk parameters by material types, whereas other methods (e.g. AnOHM, TEB and ESTM) require the thermal parameters (e.g. heat capacity) for the 
component materials. AnOHM provides a method to determine OHM parameters.

Studies exploiting Earth Observation (EO) data to derive spatial variations of $\Delta Q_{\mathrm{S}}$ are very sparse. Rigo and Parlow (2007) make use of the normalised difference vegetation index (NDVI) and net all-wave radiation $\left(Q^{*}\right)$ to obtain $\Delta Q_{\mathrm{S}}$. Kato and Yamaguchi (2007) exploit the Advanced Spaceborne Thermal Emission and Reflection radiometer (ASTER) sensor system to derive $\Delta Q_{\mathrm{S}}$ as a residual from the urban energy balance. However, they do not separate the anthropogenic and storage heat flux terms.

In this paper, we use EO data to estimate spatial variations of $\Delta Q_{\mathrm{S}}$ in urban areas using the ESTM scheme. ESTM (Section 2) accounts for variations in urban morphology, land cover and land use. We evaluate ESTM at four sites with different land covers (grass, deciduous trees, asphalt and an urban canyon) with detailed observations available. We couple ESTM-SUEWS (Section 2) and use this system to address the spatial and temporal variability of $\Delta Q_{\mathrm{S}}$ in three cities in 2016 (Chrysoulakis et al. 2018): Basel (Switzerland), Heraklion (Greece) and London (UK). As clear skies are required to acquire satellite based surface temperature data, the full temporal range cannot be assessed.

\section{ESTM}

The Elemental Surface Temperature Method (ESTM) (Offerle et al. 2005a) reduces the 3-dimensional urban volume to four 1-dimensional elements (i.e. building roofs, walls, internal mass and ground (road, vegetation, etc.)). The storage heat flux is calculated from element $(i)$ surface temperatures $\left(T_{\mathrm{i}}\right)$ :

$\Delta Q_{\mathrm{S}}=\sum_{\mathrm{i}} \frac{\Delta T_{\mathrm{i}}}{\Delta t} \rho c_{\mathrm{i}} \Delta x_{\mathrm{i}} f_{\mathrm{i}}$

where $\Delta T_{\mathrm{i}} / \Delta t$ is the rate of temperature change over the period for each element $i, \rho c$ is the volumetric heat capacity, $\Delta x_{\mathrm{i}}$ is the element thickness and $f_{\mathrm{i}}$ is the plan area index of that element. So, $x_{\mathrm{i}} f_{\mathrm{i}}$ is simply the total element volume over the plan area, for each element $i$. The element layers (e.g. wall brick, insulation, wood) average internal temperatures are accounted for, with:

$\rho c \frac{\partial T}{\partial t}=-\frac{\partial Q}{\partial x}=-\frac{\partial}{\partial x}\left(-k \frac{\partial T}{\partial x}\right)$

where $Q$ is the heat flux through the surface and $k$ is the thermal conductivity. The surface temperature of internal building elements (floors, ceiling and internal walls) is determined from setting the conductive heat transfer out of (in to) the surface equal to the radiative and convective heat losses (gains), as described by Offerle et al. (2005a).
To facilitate ESTM usage, the scheme is incorporated into the Surface Urban Energy and Water Balance Scheme (SUEWS) (Järvi et al. 2011, 2014; Ward et al. 2016; Järvi et al. 2019). This simulates the urban radiation, energy, water and $\mathrm{CO}_{2}$ fluxes with each grid characterised by the fractions of seven surface types: paved (e.g. roads, sidewalks), buildings, evergreen trees/shrubs, deciduous trees/shrubs, grass, bare soil and water. At each time step, both the surface water state (Grimmond and Oke 1991) and the soil moisture below each surface type (excluding water bodies) are calculated. To force SUEWS, the minimum meteorological data required are downward shortwave radiation, wind speed, (outdoor) air temperature, relative humidity, atmospheric pressure and precipitation (Table 1).

\section{Evaluation for the heat storage for simple surfaces}

\subsection{Methods}

Given the difficulty of measuring storage heat flux in complex urban areas, we evaluate the performance of ESTM for individual components of the urban environment. The four sites have single land covers: asphalt surface in Säve, near Gothenburg, Sweden, day of year (DOY) 43-106 (Jansson et al. 2006); long grass site in Basel, Switzerland, DOY 197-327 (Parlow et al. 2014); street canyon (Torggatan) in Gothenburg, Sweden, DOY 1-213 (Offerle et al. 2007) and a deciduous forest site, Morgan-Monroe State Forest (MMSF), USA, DOY 60-365 (Oliphant et al. 2004). Material properties for the different sites are given in Table 2.

The meteorological forcing data are compiled from nearby weather observation sites. Evaluation data for ground heat flux are derived from heat flux plates (Säve and Basel). Evaluation data from Torggatan (Gothenburg) where compiled from unshielded fine-wire thermocouples (TC) (Omega, T-type, $0.127 \mathrm{~mm}$ ) measured surface temperature affixed to the surface facets with a thin layer of adhesive including indoor temperature observation using Tinytag sensors (Offerle et al. 2007). Evaluation data for the deciduous forest (MMSF) are soil, air and biomass storages heat fluxes determined from soil heat flux plates, thermocouples and ventilated thermistors (Oliphant et al. 2004).

\subsection{Evaluation results for individual surfaces}

The ESTM scheme can satisfactorily estimate $\Delta Q_{\mathrm{S}}$ for the four test sites (Fig. 1). The best performance is for the grass (mean absolute error $(\mathrm{MAE})=5 \mathrm{~W} \mathrm{~m}^{-2}$ ). The deciduous forest and asphalt MAE are $16 \mathrm{~W} \mathrm{~m}^{-2}$ and larger for the urban canyon $\left(\mathrm{MAE}=49 \mathrm{~W} \mathrm{~m}^{-2}\right.$, Fig. 1). The mean bias error 
Table 1 Variables and parameters used by SUEWS and ESTM. More details are provided in Section 3

\begin{tabular}{|c|c|c|}
\hline Variable & Description & Source \\
\hline \multicolumn{3}{|l|}{ Meteorological } \\
\hline$T_{\mathrm{a}}$ & Ambient air temperature $\left({ }^{\circ} \mathrm{C}\right)$ & Observed \\
\hline$W_{\mathrm{s}}$ & Wind speed (m/sm s-1) & Observed \\
\hline$K_{\text {down }}$ & Incoming shortwave radiation $\left(\mathrm{W} \mathrm{m}^{-2}\right)$ & Observed \\
\hline Rain & Rain fall (mm) & Observed \\
\hline$P$ & Barometric pressure $(\mathrm{kPa})$ & Observed \\
\hline$T_{\mathrm{s}}$ & Surface temperature (K) & Modelled/observed \\
\hline$T_{\mathrm{LST}}$ & Surface temperature $(\mathrm{K})$ & $\mathrm{EO}$ \\
\hline$T_{\text {iair }}$ & Indoor air temperature $\left({ }^{\circ} \mathrm{C}\right)$ & Observed/modelled \\
\hline \multicolumn{3}{|l|}{ Geospatial } \\
\hline Land cover & $\begin{array}{l}\text { Seven surface types: paved (e.g. roads, sidewalks), } \\
\text { buildings, evergreen trees/shrubs, deciduous trees/shrubs, grass, bare soil and water }\end{array}$ & $\mathrm{EO} / \mathrm{LiDAR}$ \\
\hline DSM and CDSM & $\begin{array}{l}\text { DSM, digital surface model including ground and building heights; CDSM, } \\
\text { canopy digital surface model including vegetation height }\end{array}$ & $\mathrm{EO} / \mathrm{LiDAR}$ \\
\hline Land use & Five building land use types and three paved land use types & Urban Atlas \\
\hline Population density & People per hectare & Local geodata \\
\hline
\end{tabular}

$(\mathrm{MBE})$ is $<1 \mathrm{~W} \mathrm{~m}^{-2}$ at the three sites and $22.4 \mathrm{~W} \mathrm{~m}^{-2}$ for the urban canyon.

Of the four areas, two are relatively simple (grass and asphalt) and two are very complex (deciduous forest and urban canyon). In the latter cases, the detailed measurements allow the $3 \mathrm{D}$ environment influence on storage heat flux to be assessed. For example, the total $\Delta Q_{\mathrm{S}}$ of the deciduous forest includes contributions from air, leaves and branches. One explanation for the high accuracy of ESTM for the simple surfaces is that the parameters needed such as thickness, volumetric heat capacity and thermal conductivity can be set with a high accuracy as the material properties for each site can be studied in detail or derived from observed temperature profiles.

Although the more complex deciduous forest and street canyon sites have the larger scatter (Fig. 1), ESTM is able to capture the variations of $\Delta Q_{\mathrm{S}}$ in a fundamental descriptor of the city - the street (or urban) canyon (Oke et al. 2017). The uncertainty in observed $\Delta Q_{\mathrm{S}}$ in more complex environments is greater, because of both the large number of measurements involved and assumptions required (Oliphant et al. 2004, Roberts et al. 2006, Offerle et al. 2007).

\section{Application of ESTM to three cities}

\subsection{Sites and meteorological forcing data}

The three H2020 UrbanFluxes project (Chrysoulakis et al. 2018) cities are the focus of this study. The cities range in size from the mega-city of London (UK), to medium-sized central European city of Basel (Switzerland), to the small low latitude Mediterranean city of Heraklion (Greece). For each, the central part of the city and some vegetated areas are included (Fig. 2) in the (west-east $\times$ north-south) model domains (Fig. 2): Basel, $5.1 \mathrm{~km} \times 4.9 \mathrm{~km}$; London, $21.5 \mathrm{~km} \times$ $21.4 \mathrm{~km}$; and Heraklion, $13.2 \times 6.8 \mathrm{~km}$. As Heraklion is a much smaller city, the domain extends out to the surrounding rural area (Fig. 2).

As continuous forcing data (Table 1) are needed for both SUEWS-ESTM and to permit the net change of storage heat through time, the simulation time step should be $1 \mathrm{~h}$ or less. SUEWS-ESTM forcing data may come from observations (e.g. meteorological towers) or larger-scale models (e.g. meso-scale model or re-analysis data). Here, we use data from instruments installed on meteorological towers (Fig. 2) (Crawford et al. 2017; Feigenwinter et al. 2018; Stagakis et al. 2019).

It is assumed the internal building element temperature is mainly controlled by the internal air temperature $\left(T_{\text {iair }}\right)$. This is modelled following Georgitsi (2011), with a sinusoidal variation around a base indoor temperature $\left(T_{\text {base }}\right)$ assumed to be at a minimum at 04:00 and a maximum at 16:00

$$
T_{\text {iair }}=\left(1+\frac{T_{\mathrm{a}}-T_{\text {base }}}{5 \cdot T_{\text {base }}}\right)\left(T_{\text {base }}+0.4 \sin \left(\frac{3 \pi}{4} t_{\text {day }}\right)\right)
$$

$T_{\text {base }}$ is increased (decreased) as outdoor air temperature $\left(T_{\mathrm{a}}\right)$ increases (decreases). Time of day $\left(t_{\text {day }}\right)$ is expressed in decimal hours. The resulting diurnal range in $T_{\text {iair }}$ is typically within a $1-5{ }^{\circ} \mathrm{C}$. 
Table 2 ESTM surface material properties for London (L), Basel (B) and Heraklion (H) by building component (C): roof (r), wall (w), internal (i) and ground (g)

\begin{tabular}{|c|c|c|c|c|}
\hline Surface type & $\mathrm{C}$ & $\begin{array}{l}k \\
\mathrm{~W} \mathrm{~m}{ }^{-1} \mathrm{~K}^{-1}\end{array}$ & $\begin{array}{l}\rho c \\
\mathrm{MJ} \mathrm{K}^{-1} \mathrm{~m}^{-3}\end{array}$ & Materials and references \\
\hline \multirow[t]{3}{*}{ Building \#1 (L) } & $\mathrm{r}$ & 0.63 & 1.06 & Ceramic $^{3}$, slate $^{6}$, concrete ${ }^{1}$, insulation ${ }^{4}$ \\
\hline & $\mathrm{w}$ & 0.85 & 1.29 & Stone $^{7}$, concrete $^{1}$, brick $^{3}$, glass $^{3}$ \\
\hline & $\mathrm{i}$ & 0.93 & 1.50 & Concrete $^{1}$ \\
\hline \multirow[t]{3}{*}{ Building \#2 (L) } & $\mathrm{r}$ & 0.58 & 1.02 & Ceramic $^{3}$, concrete $^{1}$, insulation ${ }^{4}$ \\
\hline & $\mathrm{w}$ & 0.62 & 1.27 & Stone $^{7}$, concrete $^{1}$, brick $^{3}$, wood $^{4}$, glass $^{3}$ \\
\hline & $\mathrm{i}$ & 0.93 & 1.50 & Concrete $^{1}$ \\
\hline \multirow[t]{3}{*}{ Building \#3 (L) } & $\mathrm{r}$ & 0.25 & 1.12 & Ceramic $^{3}$, slate $^{6}$, wood ${ }^{4}$, insulation ${ }^{4}$ \\
\hline & $\mathrm{w}$ & 0.69 & 0.89 & Brick $^{3}$, quartzite $^{7}$, wood $^{4}$, insulation ${ }^{4}$, glass ${ }^{3}$ \\
\hline & $\mathrm{i}$ & 0.93 & 1.50 & Concrete $^{1}$ \\
\hline \multirow[t]{3}{*}{ Building \#4 (L) } & $\mathrm{r}$ & 0.24 & 0.75 & Ceramic $^{3}$, slate $^{6}$, wood $^{4}$, insulation ${ }^{4}$ \\
\hline & $\mathrm{w}$ & 0.52 & 0.95 & Brick $^{3}$, wood $^{4}$, insulation ${ }^{4}$, glass ${ }^{3}$ \\
\hline & $\mathrm{i}$ & 0.93 & 1.50 & Concrete $^{1}$ \\
\hline \multirow[t]{3}{*}{ Building \#5 (L) } & $\mathrm{r}$ & 0.61 & 1.12 & Aluminium $^{3}$, concrete $^{1}$, asphalt roll ${ }^{8}$, glass $^{3}$, insulation ${ }^{4}$ \\
\hline & $\mathrm{w}$ & 0.83 & 1.22 & 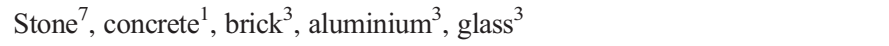 \\
\hline & $\mathrm{i}$ & 0.93 & 1.50 & Concrete $^{1}$ \\
\hline \multirow[t]{3}{*}{ Building \#6 (L) } & $\mathrm{r}$ & 0.90 & 1.50 & Aluminium $^{3}$, concrete ${ }^{1}$, asphalt roll ${ }^{8}$ \\
\hline & $\mathrm{w}$ & 0.88 & 1.42 & Concrete $^{1}$, brick $^{3}$, aluminium $^{3}$, glass ${ }^{3}$ \\
\hline & $\mathrm{i}$ & 0.93 & 1.5 & Concrete $^{1}$ \\
\hline \multirow[t]{3}{*}{ Building \#1 (H) } & $\mathrm{r}$ & 0.63 & 1.09 & Ceramic $^{3}$, water tank ${ }^{\dagger, 8}$, solar panel*, concrete $^{1}$, insulation ${ }^{4}$ \\
\hline & $\mathrm{w}$ & 0.44 & 0.80 & Concrete $^{1}$, brick $^{3}$, insulation ${ }^{4}$, glass ${ }^{3}$ \\
\hline & $\mathrm{i}$ & 0.93 & 1.50 & Concrete $^{1}$ \\
\hline \multirow[t]{3}{*}{ Building \#2 (H) } & $\mathrm{r}$ & 0.63 & 1.09 & Ceramic $^{3}$, water tank ${ }^{\dagger, 8}$, solar panel* ${ }^{*}$ concrete $^{1}$, insulation ${ }^{4}$ \\
\hline & $\mathrm{w}$ & 1.10 & 1.48 & Stone $^{7}$, concrete $^{1}$, brick $^{3}$, glass $^{3}$ \\
\hline & $\mathrm{i}$ & 0.93 & 1.50 & Concrete $^{1}$ \\
\hline \multirow[t]{3}{*}{ Building \#3 (H) } & $\mathrm{r}$ & 0.63 & 1.09 & Ceramic $^{3}$, water tank ${ }^{\dagger, 8}$, solar panel*, concrete $^{1}$, insulation ${ }^{4}$ \\
\hline & $\mathrm{w}$ & 0.45 & 0.82 & 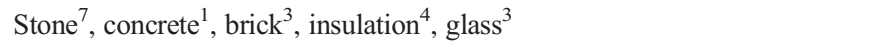 \\
\hline & $\mathrm{i}$ & 0.93 & 1.50 & Concrete $^{1}$ \\
\hline \multirow[t]{3}{*}{ Building \#4 (H) } & $\mathrm{r}$ & 0.63 & 1.09 & Ceramic $^{3}$, water tank ${ }^{\dagger, 8}$, solar panel*, concrete $^{1}$, insulation ${ }^{4}$ \\
\hline & $\mathrm{w}$ & 1.18 & 1.58 & Stone $^{7}$, concrete $^{1}$, brick $^{3}$, glass $^{3}$ \\
\hline & $\mathrm{i}$ & 0.93 & 1.50 & Concrete $^{1}$ \\
\hline \multirow[t]{3}{*}{ Building \#5 (H) } & $\mathrm{r}$ & 0.63 & 1.09 & Aluminium $^{3}$, concrete $^{1}$, insulation $^{4}$ \\
\hline & $\mathrm{w}$ & 0.50 & 0.90 & Aluminium $^{3}$, concrete $^{1}$, insulation ${ }^{4}$, glass ${ }^{3}$ \\
\hline & $\mathrm{i}$ & 0.93 & 1.50 & Concrete $^{1}$ \\
\hline \multirow[t]{3}{*}{ Building \#1 (B) } & $\mathrm{r}$ & 0.59 & 1.05 & Ceramic $^{3}$, asphalt roll ${ }^{8}$, concrete ${ }^{1}$, insulation ${ }^{4}$ \\
\hline & $\mathrm{w}$ & 0.98 & 1.44 & Stone $^{7}$, concrete $^{1}$, brick $^{3}$, glass $^{3}$ \\
\hline & i & 0.93 & 1.50 & Concrete $^{1}$ \\
\hline \multirow[t]{3}{*}{ Building \#2 (B) } & $\mathrm{r}$ & 0.18 & 1.10 & Ceramic $^{3}$, asphalt roll $^{8}$, wood $^{4}$, insulation ${ }^{4}$ \\
\hline & $\mathrm{w}$ & 0.26 & 0.79 & Brick $^{3}$, insulation ${ }^{4}$, wood $^{4}$, glass $^{3}$ \\
\hline & i & 0.93 & 1.50 & Concrete $^{1}$ \\
\hline \multirow[t]{3}{*}{ Building \#3 (B) } & $\mathrm{r}$ & 0.64 & 1.13 & Green roof ${ }^{4,2}$, aluminium ${ }^{3}$, concrete $^{1}$, asphalt roll ${ }^{8}$, solar panel ${ }^{*}$, insulation ${ }^{4}$ \\
\hline & $\mathrm{w}$ & 0.83 & 1.26 & Stone $^{7}$, concrete $^{1}$, brick $^{3}$, aluminium ${ }^{3}$, glass $^{3}$ \\
\hline & $\mathrm{i}$ & 0.93 & 1.50 & Concrete $^{1}$ \\
\hline \multirow[t]{3}{*}{ Building \#4 (B) } & $\mathrm{r}$ & 0.88 & 1.50 & Concrete $^{1}$, asphalt roll $^{8}$, wood ${ }^{4}$, \\
\hline & $\mathrm{w}$ & 0.88 & 1.43 & Concrete $^{1}$, brick $^{3}$, aluminium ${ }^{3}$, glass $^{3}$ \\
\hline & $\mathrm{i}$ & 0.93 & 1.50 & Concrete $^{1}$ \\
\hline Fast transit roads & $\mathrm{g}$ & 0.67 & 1.28 & Asphalt $^{9}$, concrete $^{1}$, gravel ${ }^{1}$, lawn $^{2}$ \\
\hline Other roads & $\mathrm{g}$ & 0.64 & 1.23 & Asphalt $^{9}$, concrete $^{1}$ \\
\hline
\end{tabular}


Table 2 (continued)

\begin{tabular}{|c|c|c|c|c|}
\hline Surface type & $\mathrm{C}$ & $\begin{array}{l}k \\
\mathrm{~W} \mathrm{~m}{ }^{-1} \mathrm{~K}^{-1}\end{array}$ & $\begin{array}{l}\rho c \\
\mathrm{MJ} \mathrm{K}^{-1} \mathrm{~m}^{-3}\end{array}$ & Materials and references \\
\hline Railways & $\mathrm{g}$ & 0.69 & 1.21 & Gravel $^{1}$, steel ${ }^{3}$, wood ${ }^{4}$ \\
\hline Bare soil & $\mathrm{g}$ & 0.85 & 1.73 & Sand $/$ soil $^{3}$ \\
\hline Evergreen trees/shrubs & $\mathrm{g}$ & 0.98 & 1.82 & Wood $^{4}$, soil $^{5}$ \\
\hline Deciduous trees/shrubs & $\mathrm{g}$ & 0.98 & 1.84 & Wood $^{4}$, soil $^{5}$ \\
\hline Grass & $\mathrm{g}$ & 1.00 & 1.86 & Lawn $^{2}$, soil $^{5}$ \\
\hline Water & $\mathrm{g}$ & 0.60 & 4.17 & Water $^{8}$ \\
\hline
\end{tabular}

The references for the values used are ${ }^{1}$ Offerle et al. (2005a); ${ }^{2}$ Campbell and Norman (1998); ${ }^{3}$ Mörtstedt and Hellsten (1992); ${ }^{4}$ Roberts et al. (2006); ${ }^{5} \mathrm{http}: / /$ www.engineeringtoolbox.com; ${ }^{6}$ Apache-Tables (2014); ${ }^{7}$ Eppelbaum et al. (2014); ${ }^{8}$ ASHRAE (2001); ${ }^{9}$ Hassn et al. (2016); Ramier et al. (2004)

${ }^{\dagger}$ Water in plastic container

* Glass in an aluminium frame

¿Lawn

\subsection{Land surface temperature}

Landsat 8 and MODIS Terra satellite data, resampled to $100 \mathrm{~m}$ resolution (Mitraka et al. 2015), are used to retrieve the land surface temperature $\left(T_{\mathrm{LST}}\right)$. For Landsat 8 , the thermal infrared sensor (TIRS) bands surface reflectance are used with the ATCOR algorithm (Richter and Schläpfer 2015) assuming a constant surface emissivity (0.98) and mid-latitude atmosphere.
MODIS Terra ( $1 \mathrm{~km} \times 1 \mathrm{~km}$ resolution) TIR bands top-ofatmosphere radiance are downscaled with a spatial-spectral unmixing method (Mitraka et al. 2015). The spectral atmospheric correction uses ATCOR. The surface spectral emissivity is estimated by determining surface cover fractions from the high-resolution visible and near-infrared (VNIR) Landsat data combined spectral libraries (Kotthaus et al. 2014).

The satellite data images are acquired before (morning) and after (evening) the peak surface temperature at times that vary
Fig. 1 Observed versus ESTM modelled $\Delta Q_{\mathrm{S}}$ at four sites: a tall grass field (Basel, Switzerland), b street canyon, (Torggatan Gothenburg, Sweden), c deciduous forest, (MorganMonroe State Forest, IN, USA) and $\mathbf{d}$ asphalt, (Säve, Gothenburg, Sweden). Statistics are MAE, mean absolute error $\left(\mathrm{W} \mathrm{m}^{-2}\right)$; $\mathrm{MBE}$, mean bias error $\left(\mathrm{W} \mathrm{m}^{-2}\right)$ and $\mathrm{N}$ number of 30 min periods evaluated
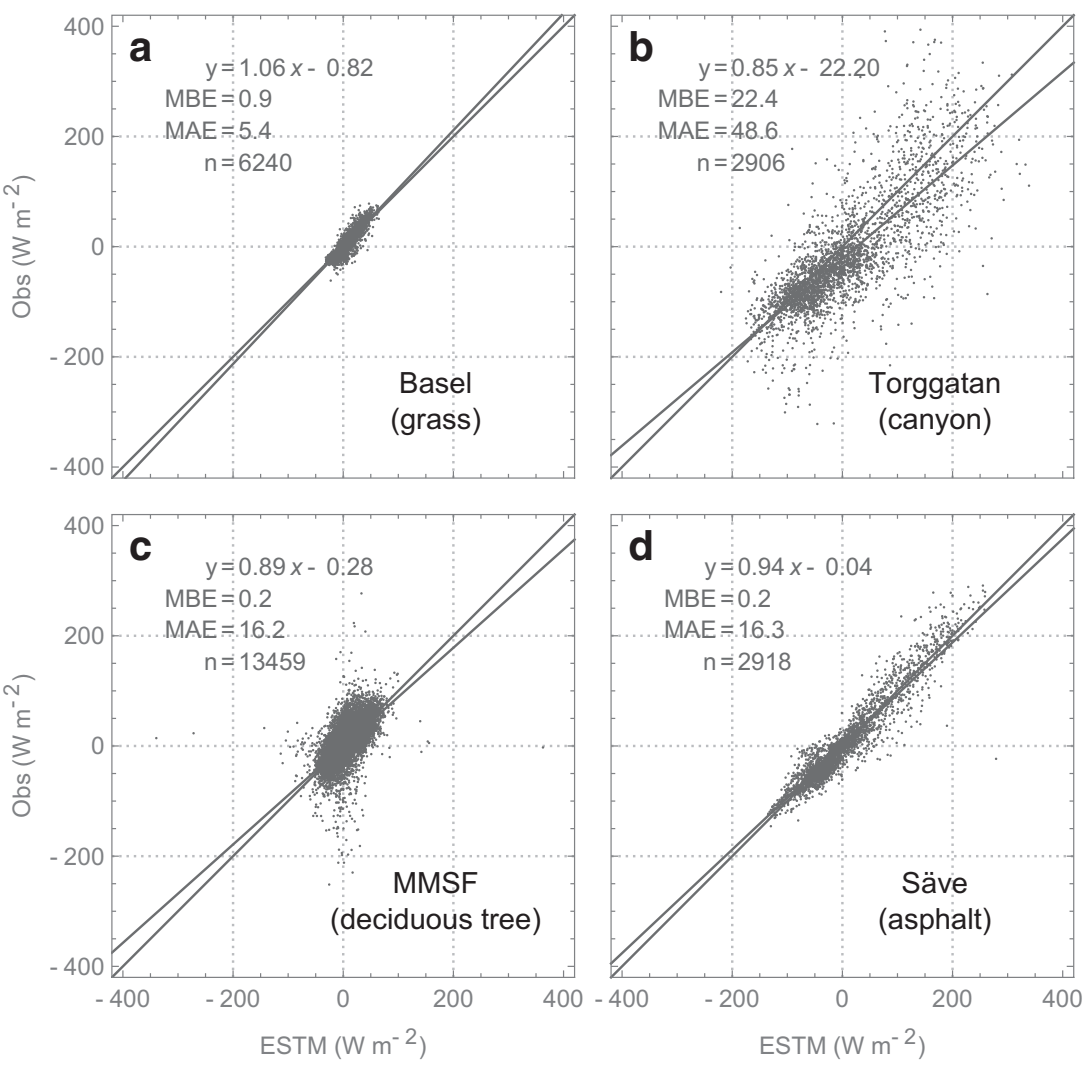


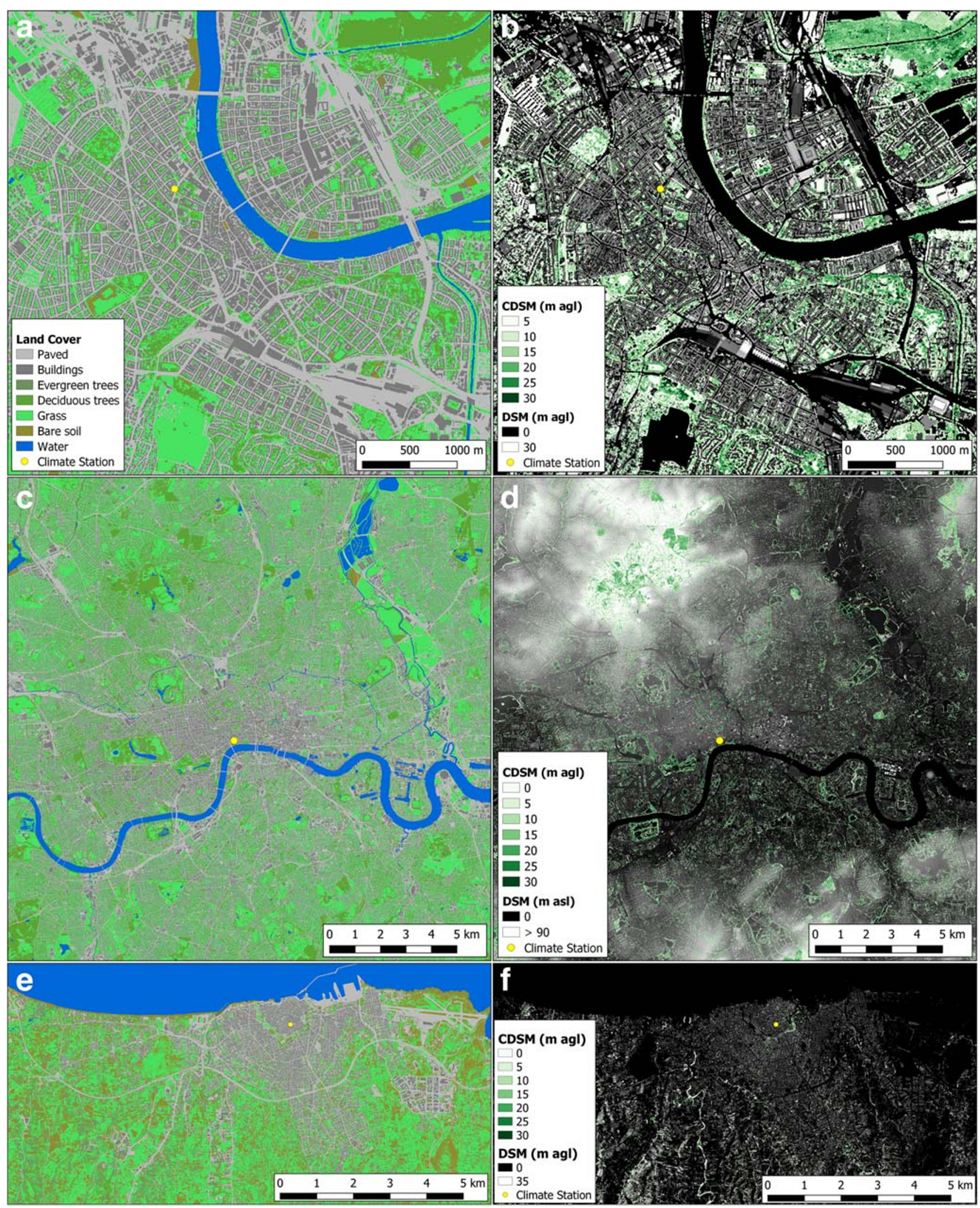

Fig. 2 a, c, e Land cover and b, d, f digital surface model (DSM) and canopy DSM (CDSM) datasets for a, b Basel, Switzerland, c, d London, UK, e, f Heraklion, Greece. Note the different scales for each study site as well as height reference. Spatial resolution is $1 \mathrm{~m}$ 
Table 3 Timing of satellite overpasses and number of images used

\begin{tabular}{llll}
\hline \multirow{2}{*}{ City } & \multirow{2}{*}{\begin{tabular}{l} 
Number of acquisitions \\
\cline { 3 - 4 }
\end{tabular}} & \multicolumn{2}{l}{ Time spans for acquisitions } \\
\cline { 3 - 4 } & (Morning/evening) & Morning & Evening \\
\hline Basel & $205(122 / 83)$ & $09: 50-11: 35$ & $20: 20-22: 10$ \\
Heraklion & $300(146 / 154)$ & $08: 30-09: 50$ & $19: 40-21: 05$ \\
London & $142(68 / 74)$ & $10: 25-12: 10$ & $20: 55-22: 45$ \\
\hline
\end{tabular}

between the earliest and latest overpass times indicated in Table 3 .

As $\Delta Q_{\mathrm{S}}$ is the net change in heat stored per time from changes in the surface and internal material temperatures, to use ESTM with instantaneous satellite data, a continuous time series is needed. In the morning, a sinusoidal relation between the outdoor air temperature $\left(T_{\mathrm{a}}\right)$ and surface temperature $\left(T_{\mathrm{S}}\right)$ difference is assumed (Lindberg et al. 2008, 2016):

$T_{\mathrm{s}}=a\left(\alpha_{\mathrm{smax}}\right) \sin \left(\frac{\pi}{2} \frac{t-t_{\mathrm{SR}}}{t_{\mathrm{peak}}-t_{\mathrm{SR}}}\right)+T_{\mathrm{a}}$

where $T_{\mathrm{s}}-T_{\mathrm{a}}$ is assumed to be $0 \mathrm{~K}$ at sunrise (SR) and marks the start of the sine period. The phase is modified and dependent on time of sunrise $\left(t_{\mathrm{SR}}\right)$ and time of maximum in $T_{\mathrm{S}}\left(t_{\text {peak }}\right)$. The surface temperature observations from the four evaluation sites (Section 3) were used to obtain the timing: $t_{\text {peak }}=t_{\mathrm{SR}}+0.65\left(t_{\mathrm{SS}}-t_{\mathrm{SR}}\right)$

where $t_{\mathrm{SS}}$ is the time of sunset. With no satellite acquisition, the amplitude $(a)$ is calculated as a function of maximum sun elevation angle $\left(\alpha_{\text {smax }}\right)$, as described in Lindberg et al. (2016). When satellite data are available, both a retrieved $T_{\mathrm{LST}}$ and the satellite overpass time $(t)$ are known. In a second step, a continuous $T_{\mathrm{s}}$ is calculated.

The $T_{\mathrm{s}}$ decrease in the afternoon and evening after $t_{\text {peak }}$ has a more (cf. to the morning) complicated pattern as the cooling rate reaches a maximum and then levels off (Holmer et al. 2007). To derive the cooling pattern, the observed surface temperature at the four evaluation sites (Section 3) are analysed (Fig. 3). The common pattern in the surface temperature decreases follows the NOCRA (NOcturnal Cooling RAte) model (Onomura et al. 2016) except that the maximum surface temperature cooling rate appears earlier. The different cooling phases (1a, 1b and 2, Fig. 3) are described using sine, cosine and linear fits, respectively. Onomura et al. (2016) provides details.

The Torggatan street canyon data are used to derive the built afternoon and night surface temperature cooling parameters. Phase $1 \mathrm{a}$ starts at $t_{\text {peak }}$ (i.e. cooling rate is zero) and ends at the time of maximum cooling rate $\left(t_{\text {maxcool }}=\right.$ $\left.t_{\mathrm{SS}}-0.08\left(t_{\mathrm{SS}}-t_{\mathrm{SR}}\right)\right)$. Phase $1 \mathrm{~b}$ continues until the start of Phase $2\left(t_{2, \text { start }}=t_{\mathrm{SS}}+1.5\right)$. Phase 2 ends at sunrise the next day (i.e. cooling rate is zero). The cooling rates during the three phases are:
Fig. 3 Observed mean diurnal evolution averages of the surface temperature, normalised by its average, (blue) and the surface temperature change (red) at four sites. Säve (Gothenburg, Sweden) is an asphalt lot (day of year, DOY 43-106), Torggatan (Gothenburg, Sweden) is a street canyon (DOY 1-213), BLER (Basel, Switzerland) is a tall grass field (DOY 197-327) and Morgan-Monroe (MMSF) (IN, US) is a deciduous forest (DOY 60-365). The timing of the three different surface cooling phases $1 \mathrm{a}, 1 \mathrm{~b}$ and 2 is represented in the Torggatan panel
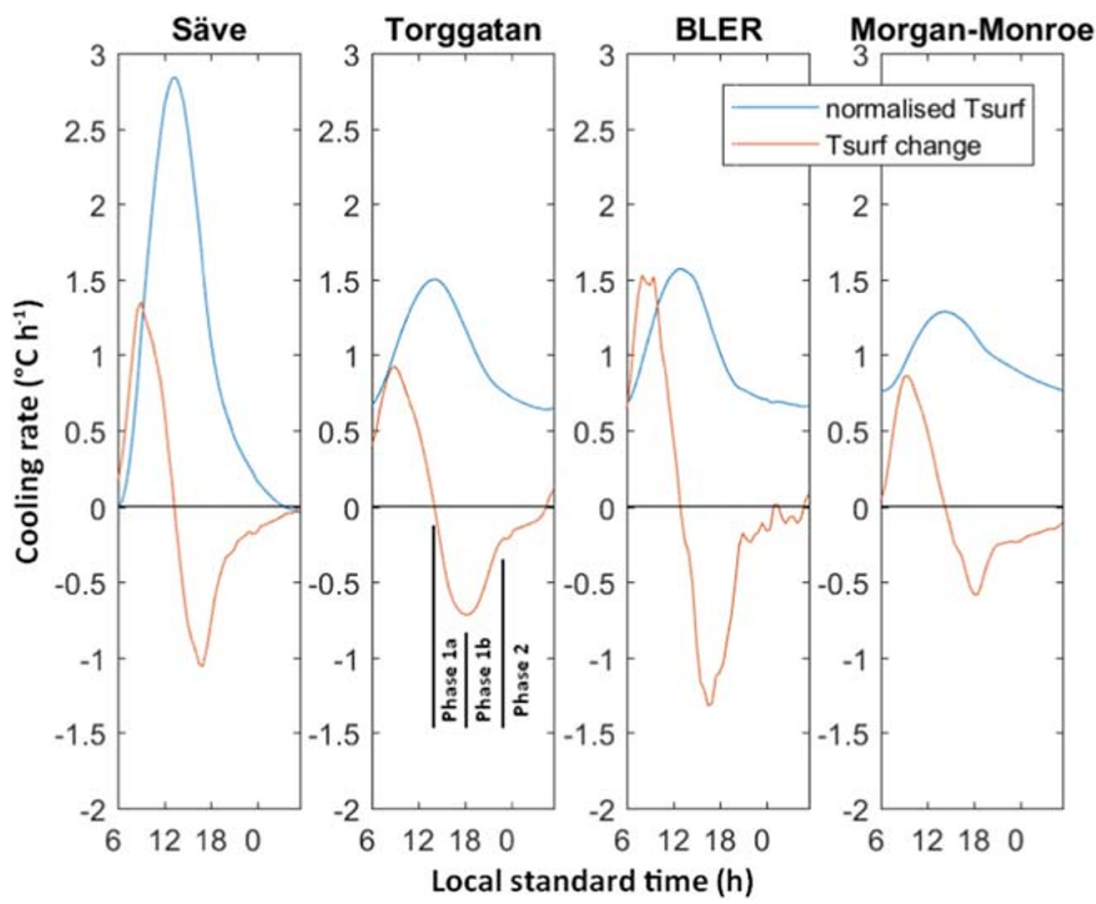


$$
\begin{aligned}
& \frac{d T_{\mathrm{s}}}{d t}=\left\{\begin{array}{c}
A_{\mathrm{r}} \sin \left(\frac{\pi}{2} \frac{t-t_{\text {peak }}}{t_{\text {maxcool }}-t_{\text {peak }}}\right) \quad \text { if } t<t_{1 \mathrm{~b}, \text { start }} \\
A_{\mathrm{r}}\left(\frac{1}{3} \cos \left(\pi\left(\frac{t-t_{\mathrm{SS}}-\left(t_{\text {maxcool }}-t_{\text {peak }}\right) / 2}{t_{\text {maxcool }}-t_{\mathrm{SS}}-\left(t_{\text {maxcool }}-t_{\text {peak }}\right) / 2}+1\right)\right)+\frac{2}{3}\right) \quad \text { if } t_{1 \mathrm{~b}, \text { start }} \leq t<t_{2, \text { start }} \\
\left(t-t_{2, \text { start }}\right) \frac{L_{2}}{t_{2, \text { start }}-\left(t_{\mathrm{SR}}+24\right)}+L_{2} \quad \text { if } t \geq t_{2, \text { start }}
\end{array}\right. \\
& \text { where } L_{2}=A_{\mathrm{r}}\left(\frac{1}{3} \cos \left(\pi\left(\frac{t_{2, \text { start }}-t_{\mathrm{SS}}-\left(t_{\text {maxcool }}-t_{\text {peak }}\right) / 2}{t_{\text {maxcool }}-t_{\mathrm{SS}}-\left(t_{\text {maxcool }}-t_{\text {peak }}\right) / 2}+1\right)\right)+\frac{2}{3}\right)
\end{aligned}
$$

When satellite $T_{\mathrm{LST}}$ are available, the temperature rate amplitude $\left(A_{\mathrm{r}}\right)$ can be retrieved in a similar way (Eq. 4$)$ to the morning surface temperature model.

The evening surface temperature profile is calculated from the daytime peak surface temperature by integrating evening surface temperature rate over time. If no evening satellite data are available, the morning scheme is used until $T_{\mathrm{s}}$ drops below $T_{a}$. It then stays at $T_{a}$ until $t_{\mathrm{SR}}$ the next day. This permits the storage heat flux modelling to continue without satellite data.

\subsection{Surface parameters from geospatial data}

For each city, SUEWS-ESTM is run with $100 \mathrm{~m} \times 100 \mathrm{~m}$ resolution. The input parameters for the models (Table 1) are prepared using Urban Multi-scale Environmental Predictor (UMEP) (Lindberg et al. 2018).

High-resolution (e.g. $1 \mathrm{~m}$ ) geospatial datasets, derived from EO data using advanced machine learning techniques and detailed spectral mixture models (Mitraka et al. 2016; Marconcini et al. 2017), are used to derive both land cover fractions and other morphological parameters (e.g. wall height, wall area and frontal area index). The digital surface models (DSM) either include both ground and building heights or only building heights above ground. In the former case, digital elevation models (DEM) of ground heights are used to obtain relative heights of object. For Heraklion, the DSM are derived from very high-resolution optical stereo imagery and for Basel and London, airborne LiDAR observations are exploited (Marconcini et al. 2017; Lindberg and Grimmond 2011).

Urban areas are often described using a street canyon (Nunez and Oke 1977) with a mean building height $\left(z_{\mathrm{H}}\right)$ and street width $(W)$. The real 3-dimensional urban morphology is simplified into a 1-dimensional infinitively long street canyon with roof, wall and ground facets. To ensure conservation of heat and momentum, the 3D to $1 \mathrm{D}$ transformation (Lindberg et al. 2015) used here is the
Martilli (2009) approach. The fractions of the three canyon facets are set to be the same as the real morphology, so that:

$z_{\mathrm{H} / W}=\frac{f_{\text {wall }}}{2\left(1-f_{\text {roof }}\right)}$

where $f_{\text {wall }}$ is the fraction of the wall area relative to the total horizontal area. For details, see Martilli (2009) or Lindberg et al. (2015).

The urban form parameters are derived from highresolution DSMs (Table 1 ). To derive $f_{\text {wall }}$, a 4-directional $3 \times 3$ kernel majority filter on the DSM is applied. Differences between the original DSM and the raster produced from the filtering are identified. A threshold is set for a wall height (e.g. $\geq 3 \mathrm{~m}$ ) allowing wall pixels to be identified. $f_{\text {roof }}$ is derived from high-resolution ground and building DSM in conjunction with a ground only DEM.

The fraction of internal building surface elements $\left(f_{\text {ibld }}\right)$ depends on fractions of wall $\left(f_{\text {wall }}\right)$ and roof $\left(f_{\text {roof }}\right)$, mean building height $\left(z_{\mathrm{H}}\right)$ and the number of rooms per floor $\left(n_{\text {room }}\right)$. An idealised indoor building geometry is assumed with two rows of equally sized rooms separated by a corridor on each floor. From this geometry, $f_{\text {ibld }}$ is:

$$
\begin{aligned}
f_{\text {ibld }}= & \left(2\left(1-\frac{1}{n_{\text {room }}}\right)\right) f_{\text {wall }}\left(f_{\text {roof }},{ }^{z_{\mathrm{H}}} / W\right) \\
& +\left(\left\lfloor\frac{z_{\mathrm{H}}}{z_{\text {floor }}}-\frac{1}{2}\right\rfloor-1\right) f_{\text {roof }}
\end{aligned}
$$

where $z_{\text {floor }}$ is the floor height (3.1 m used). In the last term, 1 is used to exclude the outer roof. With a small number of rooms per floor, $f_{\text {ibld }}$ increases rapidly but as the number grows so does the wall fraction. Beyond 10 rooms per floor, the change of the contribution of internal building surface to the total urban surface area is small.

The morphometric parameters can be derived using vector data (e.g. polygon building footprint data) also. Although vector data allow situations such as two attached buildings with different roof heights to be better resolved, these conditions 
are proportionally extremely rare. Furthermore, a direct conversion of linear vector walls will result in an overestimation of wall areas (Lindberg et al. 2015). For these reasons, a raster dataset is used in this study.

For the thermal parameters (Table 2), both land cover (e.g. buildings, paved, bare soil) and land use (e.g. residential, industrial, agricultural. areas) are considered. ESTM treats evergreen trees/shrubs, deciduous trees/shrubs, grass, bare soil and water as having constant thermal values across the city with variations in phenology and soil moisture not considered in this study.

Paved and building land cover classes are sub-divided into three and five land use classes, respectively. The Urban Atlas (EAA 2017) is used to separate roof types (e.g. suburban and city centre may have ceramic tiles and concrete roofs, respectively) and wall characteristics (e.g. fraction of glazing, insulated or not). Manual ground inspections, and comparison with Google Satellite View (ground and roofs) and Google Street View photography (walls) provide external information (Google 2016). The element layer attributes (Table 2) are based on typical construction practices.

\section{Spatial storage heat fluxes in three cities}

Storage heat fluxes are calculated for the three cities using all available satellite images ( $>50 \%$ clear sky) for 2016 in Basel (206), Heraklion (300), and London (142). As both morning and evening satellite data are available on 2016 July 19 for all sites, we select this day to show the storage heat flux maps (Fig. 4). In the morning, storage heat fluxes have large (positive values) in the dense building areas indicating warming of the surfaces. In London, and to a limited extent in Basel, tall buildings with a big volume for heat storage have large fluxes. This is apparent in the eastern part of the City of London and further east in the Canary Wharf business districts (further east) where buildings are $200 \mathrm{~m}$ and taller (cf. Figs. 2 and 4). In Basel, there are a few scattered tall buildings (generally $<80 \mathrm{~m}$ ) and in Heraklion the building height rarely exceeds $30 \mathrm{~m}$ (Fig. 2). Extensive vegetated areas, especially where trees are present (e.g. parks, Fig. 2), stand out with low $\Delta Q_{\mathrm{S}}$. The road network, most discernible in London, is where intermediate $\left(\sim 150 \mathrm{~W} \mathrm{~m}^{-2}\right)$ size $\Delta Q_{\mathrm{S}}$ values occur. Water bodies (e.g. Rhine and Thames) are not well represented by ESTM. Generally, in the evening, the areas that stored most heat during the day release (negative values) the most heat (Fig. 4).

The range of $\Delta Q_{\mathrm{S}}$ varies substantially between the cities on this date (2016 July 19), with Basel having both extremes from $\sim-340$ to $400 \mathrm{~W} \mathrm{~m}^{-2} \mathrm{cf}$. Heraklion, -190 to $200 \mathrm{~W} \mathrm{~m}^{-2}$ and London, -200 to $300 \mathrm{~W} \mathrm{~m}^{-2}$. The larger range in Basel, compared to London with its taller buildings with higher thermal mass, is caused by big differences between air and surface temperature $\left(18-32{ }^{\circ} \mathrm{C}\right)$ on 2016 July 19 (Fig. 5). The storage heat flux depends on the surface temperature, which varies with the incoming shortwave radiation and the resulting outdoor air temperature (Eqs. 1 and 2) (amongst other things). The air temperature is quite different between the three cities and the timing of the satellite overpasses relative to the air temperature change through the day (Fig. 5).

The magnitude of the storage heat flux is in principle dependent on the thermal mass (e.g. fractions of buildings, paved and vegetated areas, height and density of buildings, types of material) and the morphology of the urban setting (i.e. sky view factor). These relations are investigated for four key parameters, (i) mean building height $\left(z_{H}\right)$, (ii) wall area, (iii) building fraction and (iv) paved fraction. In Fig. 6, all summer (June, July and August) morning satellite acquisition storage heat fluxes (Table 3), retrieved from the ESTM model, are presented. The fluxes are normalised by the measured incoming shortwave $\left(K_{\downarrow}\right)$ radiation and modelled incoming longwave radiation $\left(L_{\downarrow}\right)$ for each satellite overpass $\left(\Delta Q_{\mathrm{S}} /\right.$ $\left.\left(K_{\downarrow}+L_{\downarrow}\right)\right)$. London has considerably higher $\Delta Q_{\mathrm{S}} /\left(K_{\downarrow}+L_{\downarrow}\right)$ than the other two urban areas. The overall pattern between the different measures of surface characteristics and $\Delta Q_{\mathrm{S}}$ / $\left(K_{\downarrow}+L_{\downarrow}\right)$ is similar for the three study areas. Building fraction, $\mathrm{Z}_{\mathrm{H}}$ and wall area have a linear pattern. There is a peak in $\Delta Q_{\mathrm{S}} /$ $\left(K_{\downarrow}+L_{\downarrow}\right)$ at around 0.4 in paved fraction across all three cities. This is consistent with Loridan and Grimmond (2012) analysis of eddy covariance and surface energy balance closure data for multiple sites around the world. Wall area is the surface characteristic which shows the least scattered $\Delta Q_{\mathrm{S}} /\left(K_{\downarrow}+L_{\downarrow}\right)$. This is also evident for all three study areas.

Neither building fraction nor $z_{\mathrm{H}}$ provide the complete $3 \mathrm{D}$ information of the urban area. For example, a large fraction of buildings may include a few extensive buildings (e.g. warehouses) with small areas of walls (i.e. material that will store and release heat). As building walls with large thermal mass can significantly contribute to the storage heat flux (Offerle et al. 2005a), this has the best summer daytime $\Delta Q_{\mathrm{S}}$ relation. This is evident for all three study areas (Fig. 6). When the paved fraction is high, the fraction of buildings and wall area is low and hence $\Delta Q_{\mathrm{S}} /\left(K_{\downarrow}+L_{\downarrow}\right)$ decreases from the maxima of around 0.4 (paved fraction). Thus, buildings have a larger effect on $\Delta Q_{\mathrm{S}}$ compared to paved areas. Although Basel has the highest $\Delta Q_{\mathrm{S}}$ values (Fig. 4), London has higher overall $\Delta Q_{\mathrm{S}}$ when all available morning satellite overpasses are examined for 2016, thus, exemplifying the importance of meteorological conditions on $\Delta Q_{\mathrm{S}}$. As expected, increased vegetation fractions (trees, grass) are linked to a decrease in $\Delta Q_{\mathrm{S}}$ (not shown) for all three study areas. 

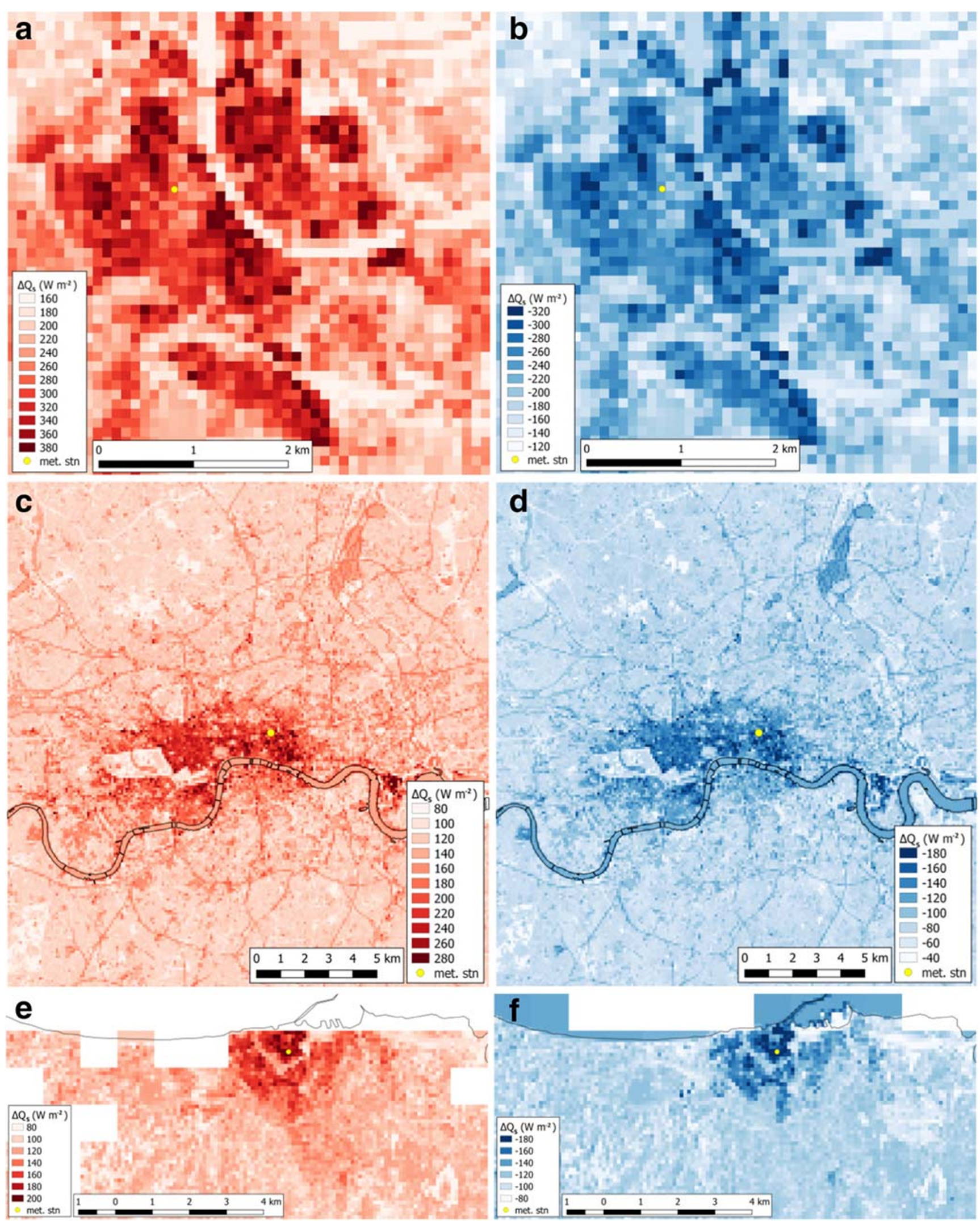

Fig. 4 Spatial distribution of $\Delta Q_{\mathrm{S}}$, modelled with ESTM on 2016 July 19 for a, b Basel at a 10:55 b 20:30, c, d London at c 10:55, d 22:05 and e,f Heraklion at 09:20 and f 20:25. Spatial resolution: $100 \mathrm{~m} \times 100 \mathrm{~m}$.

Meteorological station (yellow dot). Cloud-masked areas (white). Note that the scales are different between maps 
Fig. 5 Observed local standard time air temperature (solid line) and shortwave downward radiation (dashed line) for the three cities on 2016 July 19. Arrows indicate time for satellite overpasses

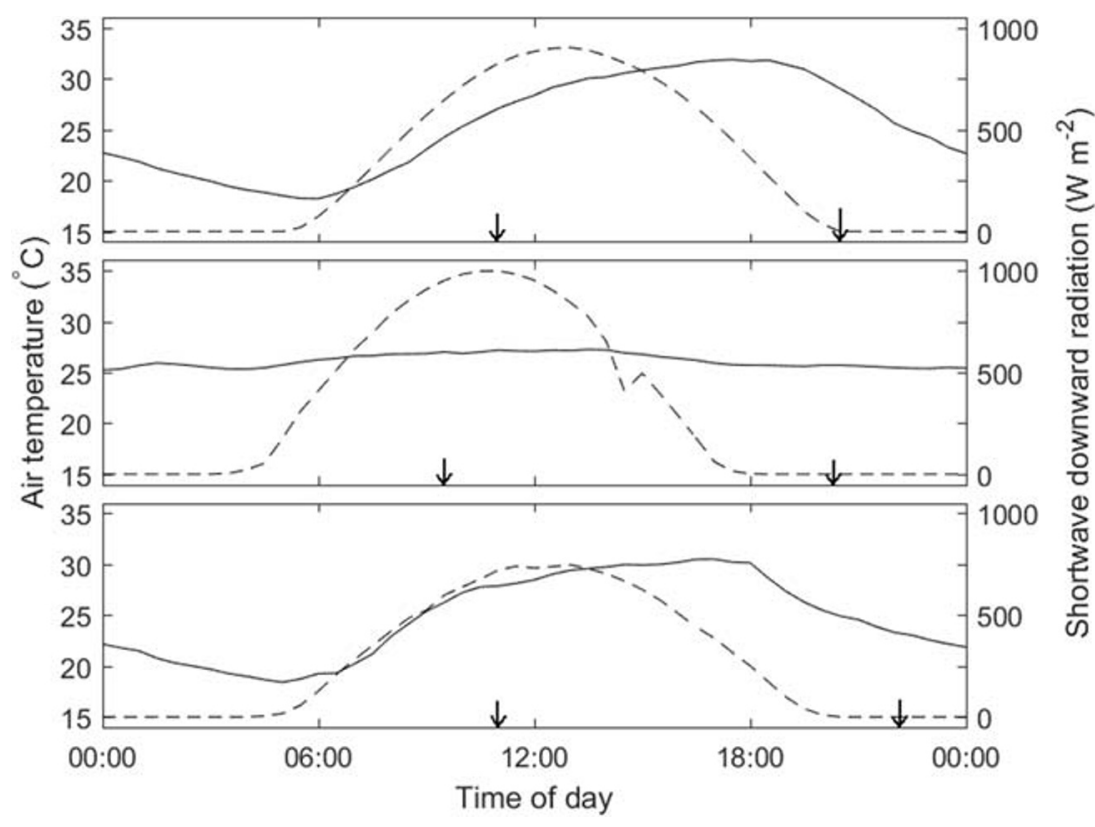

\section{Concluding remarks}

The SUEWS-ESTM scheme (available since version 2017c) is used to model $\Delta Q_{\mathrm{S}}$ in urban areas using EO data combined with ground-based meteorological forcing data and surface morphology, land cover and land use information.

Initial ESTM evaluation for four common urban surface types (grass, asphalt, deciduous trees, urban canyon) surfaces have good agreement (grass, MAE $\sim 5 \mathrm{~W} \mathrm{~m}^{-2}$; asphalt, MAE $\sim 16 \mathrm{~W} \mathrm{~m}^{-2}$; deciduous trees, MAE $\sim 16 \mathrm{~W} \mathrm{~m}^{-2}$; urban canyon, MAE $\sim 49 \mathrm{~W} \mathrm{~m}^{-2}$ ) between modelled and observed values.

Exploiting EO data to derive $\Delta Q_{\mathrm{S}}$ is challenging but the method presented has promise and allows the spatial variability of $\Delta Q_{\mathrm{S}}$ to be explored. The impervious surfaces (paved and buildings) contributes most to $\Delta Q_{\mathrm{s}}$. Building wall area seems to explain variation of $\Delta Q_{\mathrm{S}}$ most consistently. Up to about 0.4 paved fraction, the increase is associated with a clear increase in $\Delta Q_{\mathrm{S}} /\left(K_{\downarrow}+L_{\downarrow}\right)$; beyond this, $\Delta Q_{\mathrm{S}} /\left(K_{\downarrow}+L_{\downarrow}\right)$ decreases. As areas with larger paved fraction, the fraction of buildings and wall area decreases, reducing the thermal mass required for high values of $\Delta Q_{\mathrm{S}}$. The three cities have similar patterns between surface characteristics and $\Delta Q_{\mathrm{S}} /\left(K_{\downarrow}+L_{\downarrow}\right)$. However, areas with higher urban density (e.g. central London) have larger fluxes as the greater building volume contributes to the $\Delta Q_{\mathrm{S}}$ term.

There are several challenges to estimating $\Delta Q_{\mathrm{S}}$. Some issues are intrinsic to using EO satellites for $T_{\mathrm{LST}}$ : the bias to clear sky conditions, and the momentary but infrequent nature of their sampling. The latter is critical given $\Delta Q_{\mathrm{S}}$ is a measure of the change in energy stored (or released) within the urban volume. We have resolved this by constructing a continuous $T_{\mathrm{s}}$ dataset starting from the Lindberg et al.'s (2008) methodology. The original linear relation between maximum solar elevation and maximum $\left(T_{\mathrm{a}}-T_{\mathrm{S}}\right)$ for clear days is combined with diurnal sinusoidal variations in $T_{\mathrm{S}}$ and clearness index (i.e. weather conditions) to adjust $T_{\mathrm{S}}$. Here, $T_{\mathrm{LST}}$ is used to derive the $T_{\mathrm{a}}$ and $T_{\mathrm{s}}$ difference. Thus, as $T_{\mathrm{a}}$ controls the change in both $\left(T_{\mathrm{a}}\right.$ and $\left.T_{\mathrm{s}}\right)$, this may cause $\Delta Q_{\mathrm{S}}$ discrepancies, especially if $T_{\mathrm{a}}$ variability is not accounted for. Improvements in surface temperature for different facets and their relation to different cooling/heating rates are being explored (Morrison et al. 2018, 2020).

Other challenges are information received by the satellite sensor, i.e. what surfaces are seen from the sensor used to derive $T_{\mathrm{LST}}$. This is a well-known issue (Voogt 2008; Voogt and Oke 1997; Morrison et al. 2018, 2020) and not considered in this study. Furthermore, the downscaling procedure can introduce biases in $T_{\mathrm{LST}}$ (Mitraka et al. 2015). In addition, the accuracy and up-to-date status of the spatial information should also be considered. Although urban areas might seem relatively static, central London is undergoing constant urban densification (Ward and Grimmond 2017). These factors will impact the estimated $\Delta Q_{\mathrm{S}}$ if the data used are not current. In the application here, material properties such as albedo, emissivity, volumetric heat capacity and thermal conductivity (Table 2) do not vary with phenology and hydrology or other factors through the year. Yet, soil moisture will vary the soil thermal properties and LAI changes of vegetated surfaces modulate the intra-annual surface albedo. However, these effects are generally small due to the small contribution to $\Delta Q_{\mathrm{S}}$ from these land covers compared with built-up surfaces.

The SUEWS-ESTM scheme is available via UMEP (https://umep-docs.readthedocs.io/), through stand-alone versions (https://suews-docs.readthedocs.io/) or via SuPy (https:// supy.readthedocs.io/), a Python-enhanced urban climate 

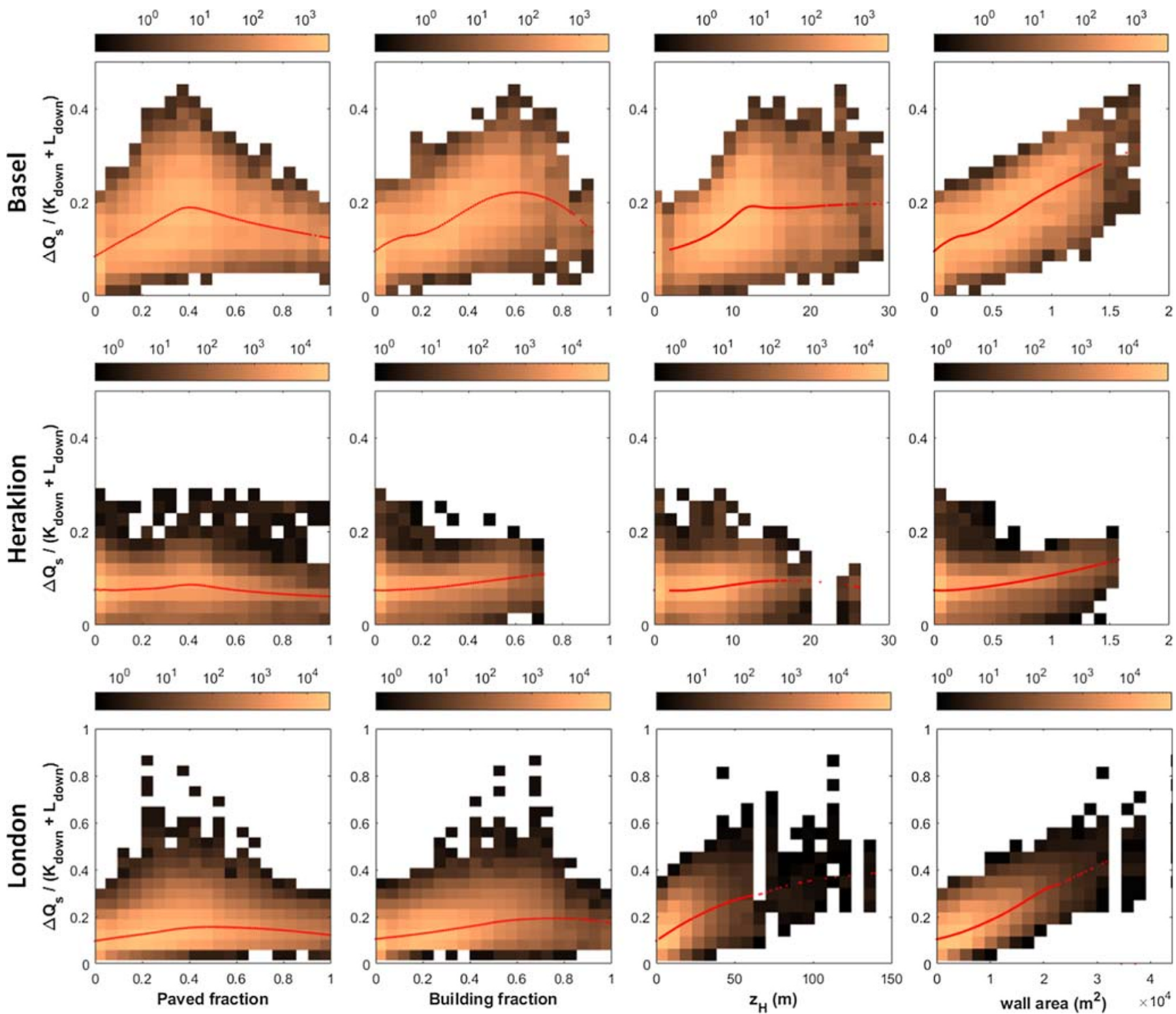

Fig. 6 Frequency (log scale) of storage heat flux normalised by incoming all-wave radiation with (col 1) paved fraction (col 2) building fraction, (col 3) mean building height and (col 4) wall area in (row 1) Basel, (row 2) Heraklion and (row 3) London. Frequencies are for all images in JJA

(Table 3 gives number of morning acquisitions). Scales differ between sub-plots. The $\Delta Q_{\mathrm{S}}$ fluxes are calculated with the ESTM. Red lines are locally estimated scatterplot smoothing (LOESS) curves

model with SUEWS as its computation core (Sun and Grimmond 2019).

Acknowledgements We would also like to thank Brian Offerle and Shiho Onomura for providing source code and knowledge about the ESTM scheme. The Greater London Authority LiDAR dataset are used courtesy of Matthew Thomas (Greater London Authority) and data from a NERC/ ARSF (GB08/19) flight.

Funding information Open access funding provided by University of Gothenburg. Financial support was provided by H2020-EO-1-2014 Project 637519: URBANFLUXES. Other support was received by FORMAS, the Swedish Research Council for Environment, Agricultural Sciences and Spatial Planning (2012-00381), UK-China Research \& Innovation Partnership Fund through the Met Office
Climate Science for Service Partnership (CSSP) China as part of the Newton Fund (SG, TS); and EPSRC (EP/N009797/1) LoHCool.

\section{Appendix}

\section{ESTM surface material properties}

The Urban Atlas land use (EEA 2017) classes are used. These distinguish areas based on the average degree of soil sealing (SL) into the following:

1. Continuous urban fabric (SL $>80 \%)$

2. Discontinuous dense urban fabric (SL 50-80\%) 
3. Discontinuous medium density urban fabric (SL 30-50\%)

4. Discontinuous low-density urban fabric (SL 10-30\%)

5. Discontinuous very low-density urban fabric (SL $1 .<$ $10 \%)$

6. Industrial, commercial, public, military and private unit

7. Fast transit roads and associated land

8. Other roads and associated land

9. Railways and associated land

Table 2 summarises the thermal parameters thermal conductivity $(k)$ and heat capacity $(\rho c)$ used for the different surface types. The values are averages of the layers of each of the surface types, scaled by their respective thickness. The building surface types are divided into the roof, wall and internal elements.

Open Access This article is licensed under a Creative Commons Attribution 4.0 International License, which permits use, sharing, adaptation, distribution and reproduction in any medium or format, as long as you give appropriate credit to the original author(s) and the source, provide a link to the Creative Commons licence, and indicate if changes were made. The images or other third party material in this article are included in the article's Creative Commons licence, unless indicated otherwise in a credit line to the material. If material is not included in the article's Creative Commons licence and your intended use is not permitted by statutory regulation or exceeds the permitted use, you will need to obtain permission directly from the copyright holder. To view a copy of this licence, visit http://creativecommons.org/licenses/by/4.0/.

\section{References}

Apache-Tables (2014) IES Virtual Environment. Retrieved from https:// help.iesve.com/ve2018/. Accessed 2016-09-01

ASHRAE (2001) ASHRAE fundamentals handbook 2001 (SI edition). American Society of Heating, Refrigerating, and Air-Conditioning Engineers.

Campbell G S, Norman JMN (1998) An introduction to environmental biophysics. Springer-Verlag New York, pp 286.

Chrysoulakis $\mathrm{N}$ et al (2018) Urban energy exchanges monitoring from space. Sci Rep 8:11498

Crawford B, Grimmond CSB, Ward HC, Morrison W, Kotthaus S (2017) Spatial and temporal patterns of surface-atmosphere energy exchange in a dense urban environment using scintillometry. Q J R Meteorol Soc 143:817-833

EAA (2017) The European Environment Agency - Urban Atlas. http:// www.eea.europa.eu/data-and-maps/data/urban-atlas. Accessed 2017-12-01

Eppelbaum L, Kutasov I, Pilchin A (2014) Applied geothermics. Springer

Feigenwinter C, Vogt R, Parlow E, Lindberg F, Marconcini M, Frate FD, Chrysoulakis N (2018) Spatial distribution of sensible and latent heat flux in the city of Basel (Switzerland). IEEE Journal of Selected Topics in Applied Earth Observations and Remote Sensing 11(8):2717-2723

Georgitsi E (2011) Barbican under-floor heating comfort and energy. University College London, London pp 142.

Google (2016) Google Maps [online] Retrieved from https://www. google.com/maps/. Accessed 2016-09-01

Grimmond CSB, Oke TR (1991) An evapotranspiration-interception model for urban areas. Water Resour Res 27:1739-1755
Grimmond CSB, Oke TR (1999) Heat storage in urban areas: local-scale observations and evaluation of a simple model. J Appl Meteorol 38: 922-940

Grimmond CSB, Cleugh HA, Oke TR (1991) An objective urban heat storage model and its comparison with other schemes. Atmospheric Environment, Part B 25B:311-326

Hassn A, Chiarelli A, Dawson A, Garcia A (2016) Thermal properties of asphalt pavements under dry and wet conditions. Mater Des 91:432439

Holmer B, Thorsson S, Eliasson I (2007) Cooling rates, sky view factors and the development of intra-urban air temperature differences. Geografiska Annaler: Series A, Physical Geography 89:237-248

Jansson C, Almkvist E, Jansson PE (2006) Heat balance of an asphalt surface: observations and physically-based simulations. Meteorol Appl 13:203-212

Järvi L, Grimmond CSB, Christen A (2011) The surface urban energy and water balance scheme (SUEWS): evaluation in Los Angeles and Vancouver. J Hydrol 411:219-237

Järvi L, Grimmond CSB, Taka M, Nordbo A, Setala H, Strachan IB (2014) Development of the surface urban energy and water balance scheme (SUEWS) for cold climate cities. Geosci Model Dev 7: 1691-1711

Järvi L, Havu M, Ward HC, Bellucco V, Mcfadden JP, Toivonen T, Heikinheimo V, Kolari P, Riikonen A, Grimmond CSB (2019) Spatial modelling of local-scale biogenic and anthropogenic carbon dioxide emissions in Helsinki. JGR - Atmospheres 124:8363-8384

Kato S, Yamaguchi Y (2007) Estimation of storage heat flux in an urban area using ASTER data. Remote Sens Environ 110:1-17

Kotthaus S, Smith TEL, Wooster MJ, Grimmond CSB (2014) Derivation of an urban materials spectral library through emittance and reflectance spectroscopy. ISPRS J Photogramm Remote Sens 94:194-212

Lindberg F et al (2018) Urban multi-scale environmental predictor (UMEP): an integrated tool for city-based climate services. Environ Model Softw 99:70-87

Lindberg F, Grimmond CSB (2011) Nature of vegetation and building morphology characteristics across a city: influence on shadow patterns and mean radiant temperatures in London. Urban Ecosyst 14: $617-634$

Lindberg F, Holmer B, Thorsson S (2008) SOLWEIG 1.0 - modelling spatial variations of $3 \mathrm{D}$ radiant fluxes and mean radiant temperature in complex urban settings. Int J Biometeorol 52:697-713

Lindberg F, Grimmond CSB, Martilli A (2015) Sunlit fractions on urban facets - impact of spatial resolution and approach. Urban Clim 12:65-84

Lindberg F, Onomura S, Grimmond CS (2016) Influence of ground surface characteristics on the mean radiant temperature in urban areas. Int J Biometeorol 60:1439-1452

Loridan T, Grimmond CSB (2012) Characterization of energy flux partitioning in urban environments: links with surface seasonal properties. J Appl Meteorol Climatol 51:219-241

Marconcini M, Heldens W, Frate FD, Latini D, Mitraka Z, Lindberg F (2017) EO-based products in support of urban heat fluxes estimation. Joint Urban Remote Sensing Event (JURSE) 2017:1-4

Martilli A (2009) On the derivation of input parameters for urban canopy models from urban morphological datasets. Bound-Layer Meteorol 130:301-306

Masson V (2000) A physically-based scheme for the urban energy budget in atmospheric models. Bound-Layer Meteorol 94:357-397

Mitraka Z, Chrysoulakis N, Doxani G, Del Frate F, Berger M (2015) Urban surface temperature time series estimation at the local scale by spatialspectral unmixing of satellite observations. Remote Sens 7

Mitraka Z, Frate FD, Carbone F (2016) Nonlinear spectral unmixing of Landsat imagery for urban surface cover mapping. IEEE Journal of Selected Topics in Applied Earth Observations and Remote Sensing 9:3340-3350 
Morrison W et al (2018) A novel method to obtain three-dimensional urban surface temperature from ground-based thermography. Remote Sens Environ 215:268-283

Morrison W et al (2020) Atmospheric and emissivity correction for ground-based thermography using 3D radiative transfer modelling. Remote Sens Environ. https://doi.org/10.1016/j.rse.2019.111524

Mörtstedt S-E, Hellsten G (1992) Data och diagram. Liber utbildning AB. (in Swedish) pp 100

Nunez M, Oke TR (1977) The energy balance of an urban canyon. J Appl Meteorol 16:11-19

Offerle B, Grimmond CSB, Fortuniak K (2005a) Heat storage and anthropogenic heat flux in relation to the energy balance of a central European city centre. Int J Climatol 25:1405-1419

Offerle B, Jonsson P, Eliasson I, Grimmond CSB (2005b) Urban modification of the surface energy balance in the West African Sahel: Ouagadougou, Burkina Faso. J Clim 18:3983-3995

Offerle B, Eliasson I, Grimmond CSB, Holmer B (2007) Surface heating in relation to air temperature, wind and turbulence in an urban street canyon. Bound-Layer Meteor 122:273-292

Oke TR, Cleugh HA (1987) Urban heat storage derived as energy balance residuals. Bound.-Layer Meteor. 39:233-245

Oke TR, Spronken-Smith RA, Jauregui E, Grimmond CSB (1999) The energy balance of central Mexico City during the dry season. Atmos Environ 33:3919-3930

Oke T, Mills G, Christen A, Voogt J (2017) Urban Climates. Cambridge: Cambridge University Press. https://doi.org/10.1017/ 9781139016476

Oliphant AJ et al (2004) Heat storage and energy balance fluxes for a temperate deciduous forest. Agric For Meteorol 126:185-201

Oliphant AJ, Stein S, Bradford G (2018) Micrometeorology of an ephemeral desert city, the Burning Man experiment. Urban Clim 23:53-70

Onomura S, Holmer B, Lindberg F, Thorsson S (2016) Intra-urban nocturnal cooling rates: development and evaluation of the NOCRA model. Meteorol Appl 23:339-352

Parlow E, Vogt R, Feigenwinter C (2014) The urban heat island of Baselseen from different perspectives. Erde 145:96-110

Ramier D, Berthier E, Andrieu H (2004) An urban lysimeter to assess runoff losses on asphalt concrete plates. Physics and Chemistry of the Earth, Parts A/B/C 29:839-847

Richter R, Schläpfer D (2015) ATCOR-2/3 User Guide, Version 9.0.0. DLR, ReSe Applications, Switzerland
Rigo G, Parlow E (2007) Modelling the ground heat flux of an urban area using remote sensing data. Theor Appl Climatol 90:185-199

Roberts SM, Oke TR, Grimmond CSB, Voogt JA (2006) Comparison of four methods to estimate urban heat storage. J Appl Meteorol Climatol 45:1766-1781

Rocklöv J, Ebi K, Forsberg B (2011) Mortality related to temperature and persistent extreme temperatures: a study of cause-specific and agestratified mortality. Occup Environ Med 68:531

Schär C, Vidale PL, Lüthi D, Frei C, Häberli C, Liniger MA, Appenzeller $\mathrm{C}$ (2004) The role of increasing temperature variability in European summer heatwaves. Nature 427:332

Stagakis S, Chrysoulakis N, Spyridakis N, Feigenwinter C, Vogt R (2019) Eddy covariance measurements and source partitioning of $\mathrm{CO} 2$ emissions in an urban environment: application for Heraklion, Greece. Atmos Environ 201:278-292

Sun T, Grimmond S (2019) A Python-enhanced urban land surface model SuPy (SUEWS in Python, v2019.2): development, deployment and demonstration. Geosci. Model Dev 12:2781-2795

Sun T, Wang ZH, Oechel WC, Grimmond S (2017) The Analytical Objective Hysteresis Model (AnOHM v1.0): methodology to determine bulk storage heat flux coefficients. Geosci. Model Dev 10:2875-2890

Thorsson S, Rocklöv J, Konarska J, Lindberg F, Holmer B, Dousset B, Rayner D (2014) Mean radiant temperature - a predictor of heat related mortality. Urban Climate 10, Part 2:332-345

UN (2015) United Nations, Department of Economic and Social Affairs, Population Division. World Urbanization Prospects: The 2014 Revision, (ST/ESA/SER.A/366)

Voogt JA (2008) Assessment of an urban sensor view model for thermal anisotropy. Remote Sens Environ 112:482-495

Voogt JA, Oke TR (1997) Complete urban surface temperatures. J Appl Meteorol 36:1117-1132

Ward HC, Kotthaus S, Järvi L, Grimmond CSB (2016) Surface urban energy and water balance scheme (SUEWS): development and evaluation at two UK sites. Urban Clim 18:1-32

Ward HC, Grimmond CSB (2017) Assessing the impact of changes in surface cover, human behaviour and climate on energy partitioning across greater London. Landscape and Urban Planning 165:142-61. https://doi.org/10.1016/j.landurbplan.2017.04.001

Publisher's note Springer Nature remains neutral with regard to jurisdictional claims in published maps and institutional affiliations. 